\title{
ifn- $y$-dependent secretion of IL-10 from Th1 cells and microglia/macrophages contributes to functional recovery after spinal cord injury
}

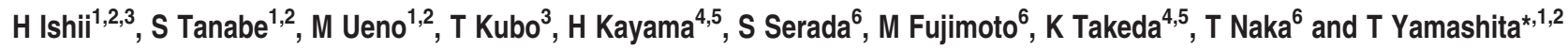

Transfer of type-1 helper T-conditioned (Th1-conditioned) cells promotes functional recovery with enhanced axonal remodeling after spinal cord injury $(\mathrm{SCl})$. This study explored the molecular mechanisms underlying the beneficial effects of pro-inflammatory Th1-conditioned cells after SCl. The effect of Th1-conditioned cells from interferon- $\gamma$ (ifn- $\gamma$ ) knockout mice (ifn- $\gamma^{-I-}$ Th1 cells) on the recovery after SCl was reduced. Transfer of Th1-conditioned cells led to the activation of microglia (MG) and macrophages (MФs), with interleukin 10 (IL-10) upregulation. This upregulation of IL-10 was reduced when ifn- ${ }^{-1-}$ Th1 cells were transferred. Intrathecal neutralization of IL-10 in the spinal cord attenuated the effects of Th1-conditioned cells. Further, IL-10 is robustly secreted from Th1-conditioned cells in an ifn- $y$-dependent manner. Th1-conditioned cells from interleukin 10 knockout (il-10 ${ }^{-l-}$ ) mice had no effects on recovery from SCl. These findings demonstrate that ifn- $\gamma$-dependent secretion of IL-10 from Th1 cells, as well as native MG/MФs, is required for the promotion of motor recovery after SCl.

Cell Death and Disease (2013) 4, e710; doi:10.1038/cddis.2013.234; published online 4 July 2013

Subject Category: Neuroscience

In mammals, once the central nervous system (CNS) is injured, in contrast to peripheral nervous system, neural regeneration and functional recovery are very limited. ${ }^{1}$ Until recently, immune reactions have been considered detrimental after CNS injuries. For example, infiltrating macrophages (MФs) and resident microglia (MG) are considered deleterious to recovery after CNS injuries ${ }^{2-4}$ and T cells are pathogenic in the injured CNS. ${ }^{4-6}$ Hence, massive dose of glucocorticoid has been infused to patients after spinal cord injury (SCI) to attenuate immune reactions in the CNS, although there are no convincing evidences that prove significant efficacy of the treatment. However, in some conditions, T cells are beneficial for repair of the injured CNS, although this notion remains controversial. $^{4,7-9}$ These contradictory findings regarding the role of $\mathrm{T}$ cells after CNS injuries could be explained by differences in the subsets of helper $T$ cells. In support of this hypothesis, a previous study demonstrated that adoptive transfer of interferon- $\gamma$ (IFN- $\gamma$ )-producing type- 1 helper T-conditioned (Th1-conditioned) cells promote functional recovery after $\mathrm{SCl}$ in mice. ${ }^{10}$ Enhanced axonal remodeling of corticospinal tract (CST) and serotonergic fibers are also observed in mice that undergo Th1-cell transfer. Although type-2 helper cells (Th2 cells) are considered neuroprotective in some situations, ${ }^{11,12}$ this previous study did not demonstrate enhanced recovery from SCl after transfer of Th2conditioned cells. ${ }^{10}$ Furthermore, transfer of IL-17-producing helper $\mathrm{T}$ (Th17) cells, pathogenic in multiple sclerosis (MS) and in an animal model of $\mathrm{MS},{ }^{13}$ limits recovery in the acute phase after $\mathrm{SCl} .{ }^{10}$ Importantly, upregulation of the anti-inflammatory/neuroprotective M2 subtype of MG/MФs was observed in the injured spinal cord after transfer of Th1 cells that had previously been considered to be involved in the onset and progression of autoimmune diseases such as MS. ${ }^{14,15}$ In the current study, we explored the mechanism underlying the restorative effects of transferred Th1 cells after $\mathrm{SCl}$ in mice.

\section{Results}

Therapeutic effects of Th1 cells after SCI depend on IFN- $\gamma$. The objective of this study was to explore the mechanism behind the effects of adoptively transferred Th1-conditioned cells on the functional recovery after $\mathrm{SCl}$. We first assessed whether IFN- $\gamma$, a major cytokine secreted by $\mathrm{Th} 1$ cells, ${ }^{16}$ was required for the effects. We isolated cluster of differentiation 4 (CD4) ${ }^{+}$T cells from spleens of wild-type

\footnotetext{
${ }^{1}$ Department of Molecular Neuroscience, Graduate School of Medicine, Osaka University, 2-2 Yamadaoka, Osaka 565-0871, Japan; ${ }^{2}$ JST, CREST, 5 Sanbancho, Tokyo 102-0075, Japan; ${ }^{3}$ Department of Neurobiology, Graduate School of Medicine, Chiba University, 1-8-1 Inohana, Chiba 260-8677, Japan; ${ }^{4}$ Laboratory of Mucosal Immunology, Department of Microbiology and Immunology, Graduate School of Medicine, Osaka University, 2-2 Yamadaoka, Osaka 565-0871, Japan; ${ }^{5}$ WPI Immunology Frontier Research Center, Osaka University, 2-2 Yamadaoka, Osaka 565-0871, Japan and ${ }^{6}$ Laboratory for Immune Signal, National Institute of Biomedical Innovation, 7-6-8 Saito-Asagi, Osaka 565-0085, Japan

${ }^{*}$ Corresponding author: T Yamashita, Department of Molecular Neuroscience, Graduate School of Medicine, Osaka University, 2-2 Yamadaoka, Osaka 565-0871, Japan. Tel: + 8166879 3661; Fax: + 8166879 3669; E-mail: yamashita@molneu.med.osaka-u.ac.jp

Keywords: Th1 cells; spinal cord injury; microglia macrophages; interleukin 10

Abbreviations: CNS, central nervous system; CST, corticospinal tract; SCI, spinal cord injury; IFN- $\gamma$, interferon- $\gamma$; IL-10, interleukin 10; Th1 cells, type-1 helper T cells; Th2 cells, type-2 helper T cells; Th17, IL-17-producing helper T cells; NT-3, neurotrophin 3; CD4, cluster of differentiation 4; PBS, phosphate-buffered saline; GDNF, glia-derived neurotrophic factor; ELISA, enzyme-linked immunosorbent assay

Received 28.10.12; revised 06.5.13; accepted 03.6.13; Edited by A Verkhratsky
} 
(WT) and interferon- $\gamma($ ifn- $\gamma)$-knockout $\left(\right.$ ifn- $\left.\gamma^{-/-}\right)$mice. The cells were then cultured with IL-2/IL-12 and anti-IL-4 neutralizing antibody to induce differentiation into Th1 cells. We confirmed with enzyme-linked immunosorbent assay (ELISA) that IFN- $\gamma$ secretion from Th1 ifn- $\gamma^{-/-}$cells was totally abrogated compared with WT Th1 cells and Th17 cells (Figure 1a). In addition, abundant expression of T-bet, a T-box transcription factor of the Th1 master gene, ${ }^{17}$ was observed in cultured WT Th1-conditioned cells by flow cytometry (Figure 1b). T-bet in ifn- $\gamma^{-1-}$ Th1-conditioned cells was expressed at an intermediate level between Th0 and Th1 cells (Figure 1b).

Mouse vertebrae were laminectomized and the exposed spinal cords were contused at the level between thoracic vertebrae 9 (T9) and 10 (T10) by an impactor with a force of $60 \mathrm{kdyn}$. On the first day after contusion, the hindlimbs of all mice were completely paraplegic and gradually displayed partial recovery of motor function after day 1 . At 4 days after contusion SCI, $1.0 \times 10^{7} \mathrm{WT}$ and ifn- $\gamma^{-I-}$ Th1-conditioned cells were transferred intraperitoneally (i.p.) into the mice and recovery of motor function was assessed using the Basso Mouse Scale (BMS). ${ }^{18}$ Enhanced motor recovery was observed in mice that received Th1 ifn- $\gamma^{-/-}$cell transfer compared with control mice, but the extent of the improvement was less than that observed in mice receiving a transfer of WT Th1-conditioned cells (Figure 1c).

Consistent results were obtained when the grid-walk test was performed, which assesses voluntary movement control mediated by the corticospinal and the rubrospinal systems. ${ }^{19}$
Transfer of Th1 ifn- $\gamma^{-/-}$cells led to a significantly greater frequency of hindlimb dropping (mistakes) compared with that of WT Th1 cells (Figure 1d). Thus, IFN- $\gamma$ in Th1-conditioned cells contributes to improved functional recovery.

ifn- $\gamma$-dependent activation of MG by adoptive transfer of Th1-conditioned cells. Previous observations with flow cytometry after $\mathrm{SCl}$ showed that transfer of Th1-conditioned cells led to an increase in MG/MФs and to upregulation of the neuroprotective M2 subtype: $\mathrm{CD}_{206}{ }^{+}$cells among the MФs and arginase $1^{+}$(Arg1) cells among the $M G .{ }^{10}$ Morphological analysis by immunohistochemistry for ionized calciumbinding adapter molecule 1 (Iba1) in the contused spinal cord revealed that with Th1 transfer, MG/MФs increased, enlarged, and were more round compared with those in control mice (Figures $2 a$ and b). This observation is consistent with the previous data that showed both activation of MG/MФs with CD11b and CD45 immunoreactivity using flow cytometry and upregulation of the M2 subtype, which has characteristics including anti-inflammatory effects, phagocytic behavior, and a round shape compared with the pro-inflammatory, destructive, and ramified M1 subtype. ${ }^{10}$ MG/MФs were assessed quantitatively using flow cytometry $^{20}$ and microglial activation by Th1-cell transfer after $\mathrm{SCl}$ was shown to depend on IFN- $\gamma$ (Figures $2 c$ and $d$ ).

IL-10 produced from MG/MФs contributes to repair after SCI. It was hypothesized that some molecules secreted from
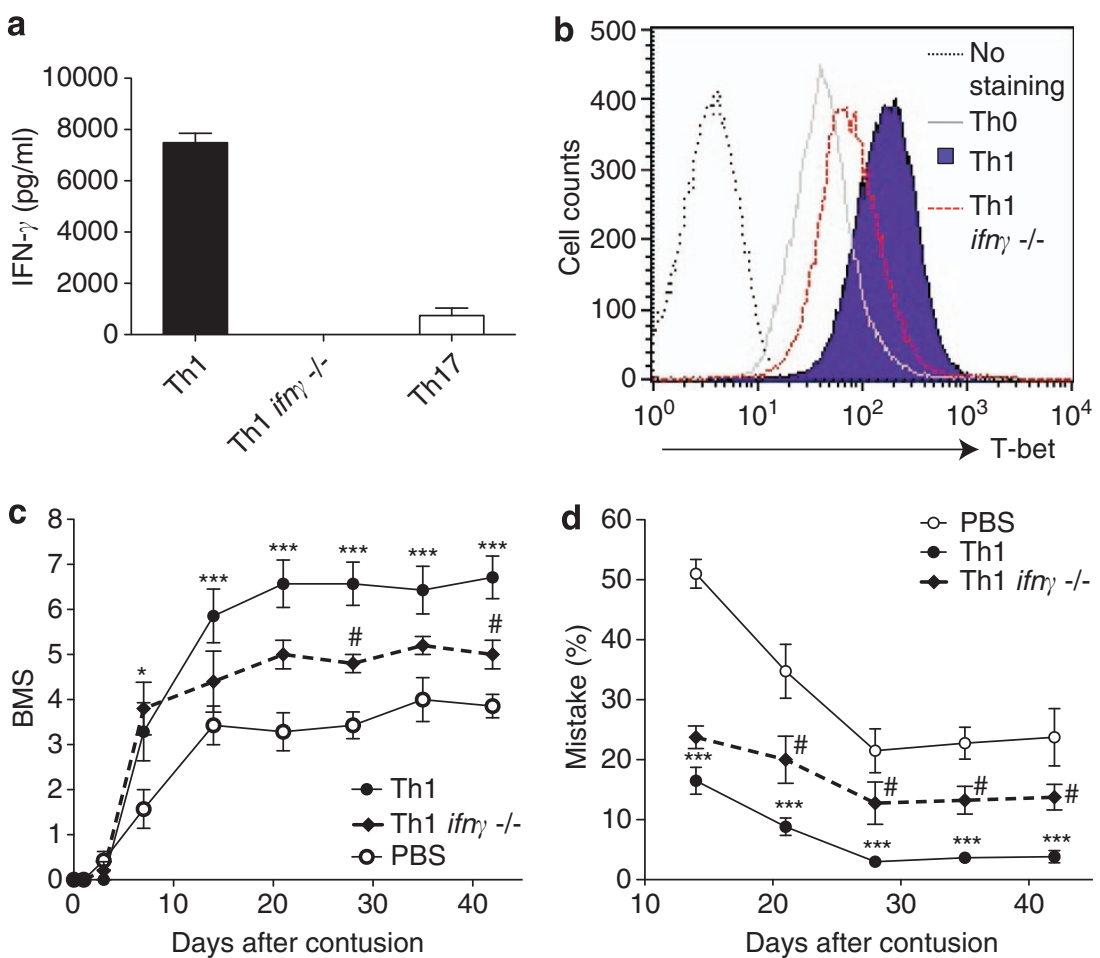

Figure 1 Improved recovery induced by Th1 cells after SCI depends on IFN- $\gamma$. Enhanced recovery from SCI by Th1 transfer is dependent on interferon- $\gamma($ ifn- $\gamma$ ) in transferred Th1 cells. (a) Level of IFN- $\gamma$ secreted from Th1 cells, Th1 ifn- ${ }^{-l-}$ cells, and Th17 cells, which was detected by ELISA $(n=3)$. (b) Comparison of T-bet production in helper T cells differentiated ex vivo, which was assessed by flow cytometry histogram. Representative data from three independent experiments. (c) Time course of hindlimb locomotion using the BMS with adoptive transfer of $1.0 \times 10^{7}$ each helper T-cell subsets (PBS, $n=7 ;$ Th1 $n=7$; Th1 ifn- $\gamma^{-1-}, n=5$ ). (d) Time course of the grid-walk test (PBS, $n=4$; Th1, $n=6$; Th1 ifn- $\gamma^{-\prime-}, n=4$ ). Data are presented as mean \pm S.E.M. ${ }^{\star} P<0.05,{ }^{\star \star *} P<0.001$ versus the PBS group, ${ }^{\#} P<0.05$ versus Th1 group (two-way ANOVA with repeated measures, Bonferroni post-test) 
a



$\leftarrow$ Rostral $-3 \mathrm{~mm} \quad-1 \mathrm{~mm} \quad 0 \mathrm{~mm} \quad 1 \mathrm{~mm} \quad 3 \mathrm{~mm} \quad$ Caudal $\rightarrow$

Th1

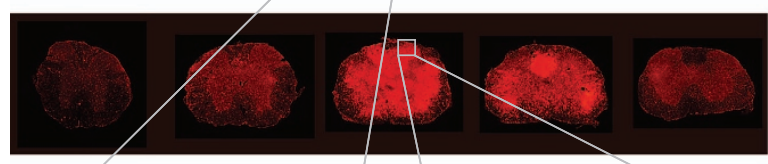

b


Forward scatter
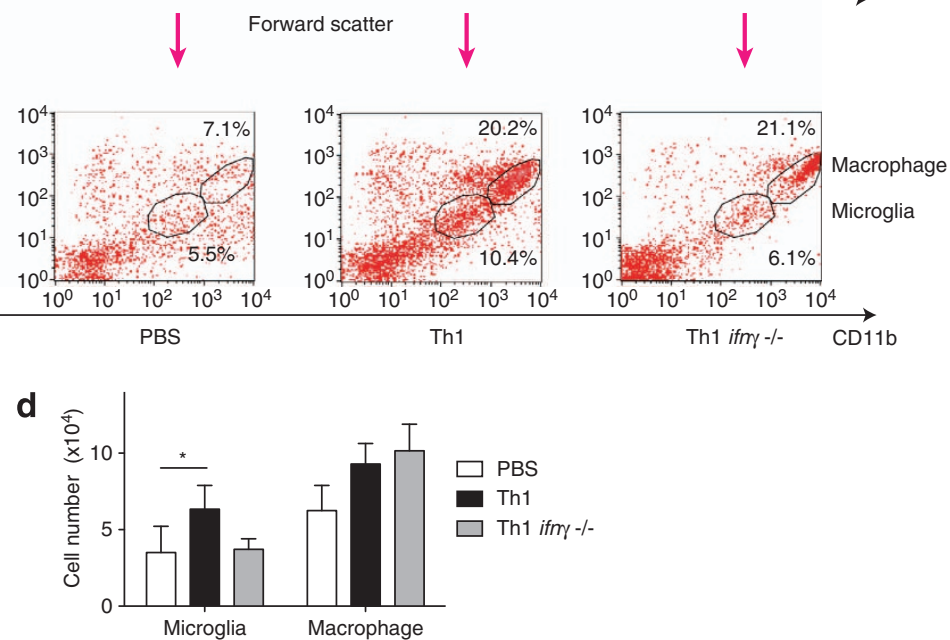

Figure 2 Microglial activation induced by Th1-cell transfer depends on IFN- $\gamma$. Adoptive transfer of Th1-conditioned cells after SCI leads to activation of MG/MФs at the injured site, and microglial activation is dependent on ifn- $\gamma$ in transferred Th1 cells. (a) Immunohistochemistry for MG/MФs labeled with anti-lba1 antibody. Spinal cords removed on day 10 after $\mathrm{SCl}$ were cut transversely. The section at $0 \mathrm{~mm}$ corresponds to the epicenter of the contusion and the distance shown is caudal from the epicenter. Scale bar, $500 \mu \mathrm{m}$. (b) Higher magnification views of (a). Scale bar, $100 \mu \mathrm{m}$. (c) Representative flow cytometry profile of MG/M day 6, 2 days after the injection of PBS or cultured T cells. Upper dot plots indicate the side-scatter/forward-scatter profile by which CD11b/CD45 profiles were gated. In lower dot plots, CD11b intermediate $\mathrm{CD} 45$ intermediate corresponds to MG, whereas CD11b high $\mathrm{CD} 45$ high corresponds to MФs. The leftmost dot plots indicate a profile using isotypematched immunoglobulins as a control. (d) The number of MG or MФs that accumulated in the spinal cord on day 6 after SCI, 2 days after the injection of PBS or Th1-conditioned cells. PBS, $n=3$; Th1, $n=4$; Th1 ifn- $\gamma^{-1-}, n=3$. Leukocytes isolated from the spinal cords of two to four mice were analyzed in each experiment. ${ }^{*} P<0.05$ (one-way ANOVA with Bonferroni post-test)

MG/MФs have a role in the enhanced functional recovery induced by Th1-cell transfer after SCl. Intracellular cytokine staining of MG/MФs indicated that interleukin 10 (IL-10), which is considered to be cerebroprotective after an ischemic stroke $^{21}$ and is one of the M2 anti-inflammatory markers, ${ }^{22}$ was upregulated in $\mathrm{MG} / \mathrm{M} \Phi$ s in the spinal cord after transfer of Th1-conditioned cells (Figure 3a). This upregulation was reduced if Th1 ifn- $\gamma^{-I-}$ cells were adoptively transferred (Figure 3a), demonstrating that IFN- $\gamma$ secreted from Th1conditioned cells contributes to IL-10 production from MG/MФs. We previously demonstrated that neutralization of IL-10 from Th1 cells attenuates the functional recovery initiated by the transfer of Th1 cells after SCl. ${ }^{10}$ However, it remains to be determined whether IL-10 secretion in the CNS 
a
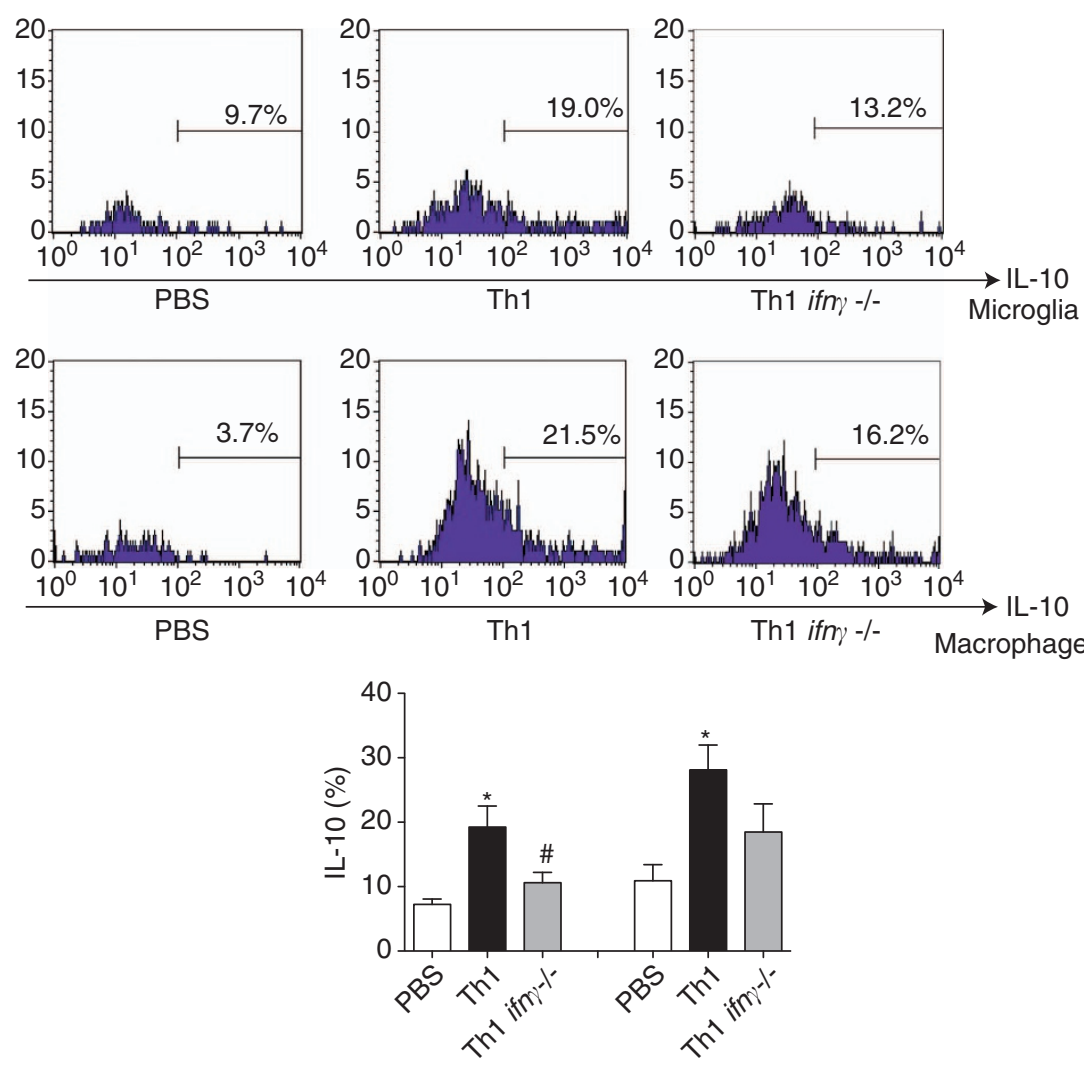

Microglia

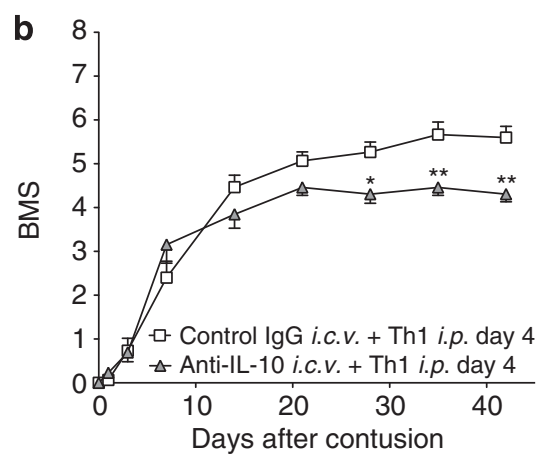

Macrophages

C

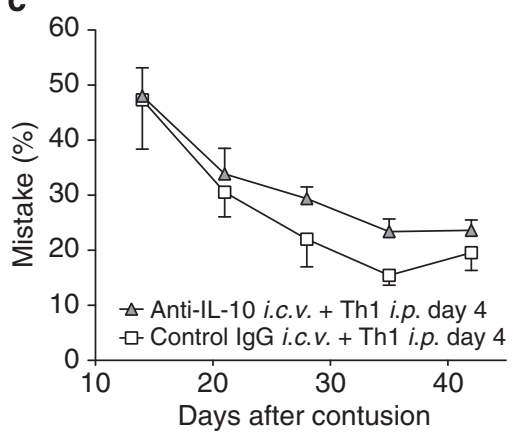



Figure 3 Neutralization of IL-10 in the CNS attenuates functional recovery by Th1 cells transfer. IL-10 expressed in the CNS partially contributes to functional recovery after SCI with adoptive transfer of Th1-conditioned cells. (a) Upper histograms: comparison of IL-10 production from MG/MФs evaluated using histograms of intracellular cytokine staining. The histogram is representative of four independent experiments. All histograms were gated from the populations of MG or MФs as shown in Figure 2c. Lower graph: quantification of IL10 production as indicated above. ${ }^{*} P<0.05$ versus the PBS group, ${ }^{\#} P<0.05$ versus Th1 group (one-way ANOVA, Bonferroni post-test). (b-d) Functional recovery from SCl evaluated by: BMS scores (b), grid-walk test (c), and inclined-plane test (d) in Th1-conditioned cell-transferred SCI mice treated with control IgG or anti-IL-10 antibody into the cerebral ventricles (i.c.v.; control rat IgG + Th1, $n=15$; anti-IL-10 + Th1, $n=13$ (BMS scores and inclined-plane test)/control lgG + Th1, $n=9$; anti-IL-10 + Th1, $n=8$ (grid-walk test)). ${ }^{*} P<0.05,{ }^{* *} P<0.01$ versus control lgG + Th1 group (two-way ANOVA with repeated measures, Bonferroni post-test) 


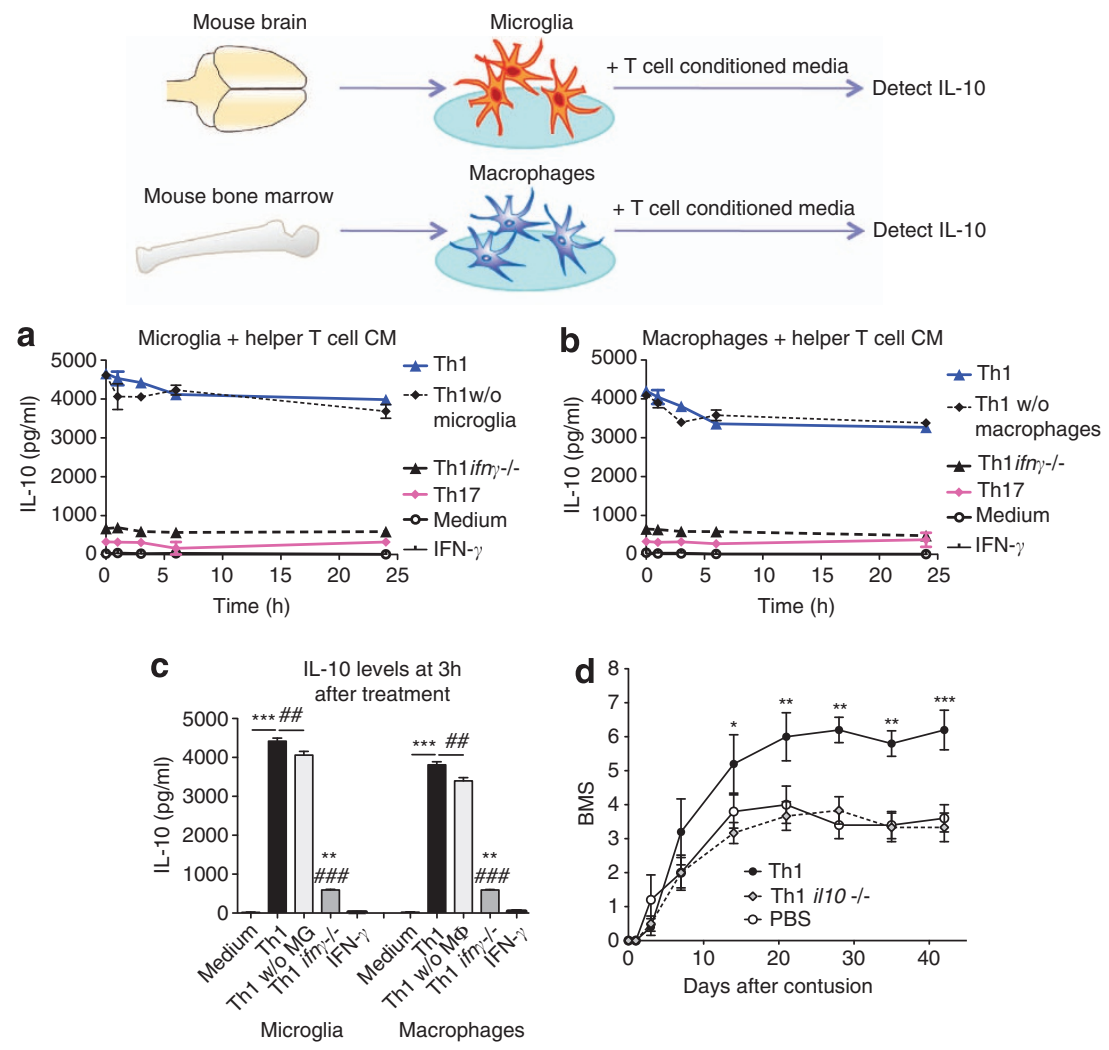

Figure 4 In vitro assay for IL-10 detection in MG/MФ culture and in vivo experiment using il-10-knockout mice. Neonatal mouse brain-derived MG or mouse femoral bone marrow-derived MФs were cultured on 96-well plate. The MG or the MФs were treated with the T-cell conditioned media (CM) or recombinant IFN- $\gamma$ and, thereafter, IL-10 levels at different time points were measured by using ELISA (schematic drawn in an upper panel). IL-10 surge from MG/MФs was not observed in the in vitro assay unlike in the injured spinal cord after Th1-cell transfer. However, Th1 cells secreted robust IL-10 in an ifn- $\gamma$-dependent manner, and this IL-10 secretion from Th1 cells had a pivotal role in improved recovery after SCl. (a) Time course of IL-10 level detected by ELISA in MG culture media after treatment with T-cell CM or IFN- $\gamma$ (medium, $n=4$; Th1, $n=4$; Th1 w/o MG: Th1 cells without MG, $n=4$; Th1 ifn- ${ }^{-1-}, n=3$; IFN- $\gamma$ (recombinant IFN- $\gamma$ at $\left.20 \mathrm{ng} / \mathrm{ml}\right), n=3$; Th17, $n=2$ ). (b) Time course of IL-10 level detected by ELISA in macrophage (MФ) culture media after treatment with T-cell CM or IFN- $\gamma$ (medium, $n=4$; Th1, $n=4$; Th1 w/o microglia (MG): Th1 cells without MФs, $n=4$; Th1 ifn- $\gamma^{-1-}, n=3$; IFN- $\gamma$ : recombinant IFN- $\gamma$ at $20 \mathrm{ng} / \mathrm{ml}, n=3$; Th17, $n=2$ ). (c) IL-10 level in MG or M $\Phi$ culture media at $3 \mathrm{~h}$ after treatment with T-cell CM or IFN- $\gamma$ (MG: medium, $n=4$; Th1, $n=4$; Th1 cells without MG, $n=4$; Th1 ifn- ${ }^{-\prime-}, n=3$; IFN- $\gamma$ : recombinant IFN- $\gamma$ at $20 \mathrm{ng} / \mathrm{ml}, n=3$; MФs: medium, $n=4$; Th1, $n=4$; Th1 w/0 MФ: Th1 cells without MG, $n=4$; Th1 ifn- $\gamma{ }^{-l-}, n=3$; IFN- $\gamma$ : recombinant IFN- $\gamma$ at $\left.20 \mathrm{ng} / \mathrm{ml}, n=3\right) .{ }^{* *} P<0.01$, ${ }^{* *} P<0.001$ versus the medium group, ${ }^{\# \#} P<0.01,{ }^{\# \#} P<0.001$ versus Th1 group (one-way ANOVA, Bonferroni post-test). (d) BMS scores in Th1 or Th1 il-10 ${ }^{-1-}$-transferred SCI mice (PBS, $n=5$; Th1, $n=5$; Th1 il-10 $\left.{ }^{-l-}, n=6\right) .{ }^{\star} P<0.05,{ }^{* \star} P<0.01,{ }^{* \star *} P<0.001$ versus the PBS group (two-way ANOVA with repeated measures, Bonferroni post-test)
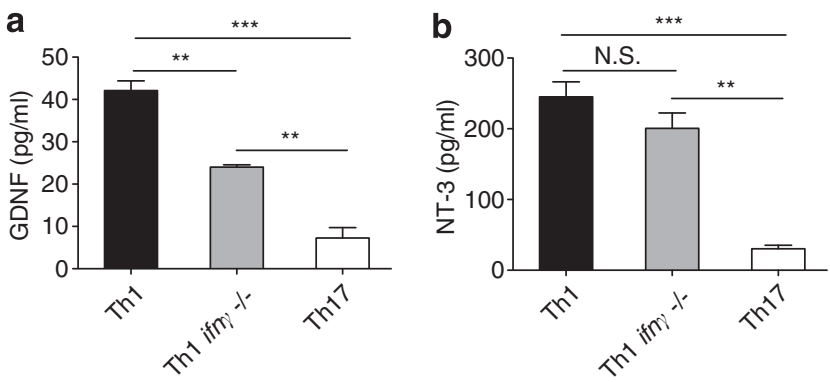

Figure 5 GDNF secretion from Th1 cells is dependent on IFN- $\gamma$. Expression of neurotrophic factors in cultured helper T cells. GDNF (a), and NT-3 (b) in the supernatant of Th1, Th1 ifn- $\gamma^{-1-}$, and Th17 cells detected by ELISA (Th1, $n=3$; Th1 ifn- ${ }^{-1-}, n=3$; Th17, $\left.n=3\right) .{ }^{* \star} P<0.01,{ }^{* \star \star} P<0.001$; NS, not significant (one-way ANOVA with Bonferroni post-test)

after Th1 transfer has neuroprotective effects, because anti-IL-10-neutralizing antibody could block not only IL-10 secretion from transferred Th1 cells but also from native cells in the injured CNS, as shown in our previous experiment.
To assess whether IL-10 produced by MG/MФs in the CNS is required for the in vivo effects, anti-IL-10-neutralizing antibody or control IgG was injected into the cerebral ventricles (i.c.v.) using an osmotic pump catheterized to the right lateral ventricle for 7 days after $\mathrm{SCl}$ in mice. Th1-conditioned lymphocytes were injected i.p. to these mice on day 4 after $\mathrm{SCl}$. Compared with treatment with control IgG, antibody infusion significantly suppressed motor recovery at time points later than 4 weeks after $\mathrm{SCl}$, as assessed by BMS scoring (Figure $3 b$ ). Although there were no significant differences observed in the grid-walk test (Figure $3 \mathrm{c}$ ), the ameliorated recovery of motor functions by Th1-cell transfer was attenuated in the inclined-plane test (Figure 3d). Therefore, IL-10 secreted from the cells in the CNS is a partial contributor to enhanced motor recovery after SCI.

ifn- $\gamma$-dependent secretion of IL-10 from Th1 cells have a pivotal role in improved recovery after $\mathrm{SCl}$. We next performed in vitro experiments to confirm whether we can recapitulate IL-10 upregulation from MG and MФs by Th1- 




Figure 6 Schematic representation showing molecular mechanism of restorative effects of transferred Th1-conditioned lymphocytes on recovery after $\mathrm{SCl}$. ifn- $\gamma$-dependent secretion of IL-10 from transferred Th1-conditioned cells contributes to an increase of $\mathrm{M} 2$ subtype of $M G / M \Phi s$, as shown by the upregulation of IL-10, arginase 1 (Arg1), and CD206, leading to restorative effects on functional recovery after $\mathrm{SCl}$

conditioned lymphocytes. First, we cultured MG from neonatal mouse brains and mouse femoral bone-derived MФs. Secretion of IL-10 was measured using ELISA after MG (Figure 4a), or MФs (Figure 4b) cultured in 96-well plates were treated with conditioned media $(\mathrm{CM})$ of Th1 cells, Th1 ifn- $\gamma^{-I}$ cells, and Th17 cells or recombinant IFN- $\gamma$ (Figure 4 upper schematic). Even at the starting point, high levels of IL10 were observed in Th1-cell group (Figures $4 a$ and b), demonstrating that $\mathrm{CM}$ of Th1 cells themselves contained abundant IL-10 compared with Th1 ifn- $\gamma^{-/-}$cells and Th17 cells. Although IL-10 expression from MG/MФs unexpectedly did not surge, IL-10 levels from MG or MФs treated with $C M$ of Th1 cells were significantly higher than only CM of Th1 cells at $3 \mathrm{~h}$ after the treatment (Figures $4 \mathrm{a}-\mathrm{c}$ ). It is suggested that comparatively small amounts of IL-10 were secreted from cultured MG/MФs in the early phase after treatment of Th1 CM. As Th1 cells robustly secreted neuroprotective IL10 (Figures $4 a$ and $b$ ), we examined whether genetic deletion of il-10 in transferred Th1-conditioned cells decreased the effects of the Th1 cells in SCl mice. As a result, Th1 interleukin 10 knockout ( $\mathrm{il}-10^{-/-}$) cells transfer completely diminished the ameliorative effects of Th1 cells transfer on hindlimb locomotion after $\mathrm{SCl}$, as assessed by BMS scoring (Figure 4d).

Th1-conditioned lymphocytes secrete neurotrophic factors. Candidate neurotrophic factors in Th1-conditioned cells that promote neuroprotection were investigated after contusion $\mathrm{SCl}$ and the expression of neurotrophic factors, such as glia-derived neurotrophic factor (GDNF) and neurotrophin 3 (NT-3), in Th1-conditioned cells was shown to be higher than that in Th17 cells, which limited functional recovery after $\mathrm{SCl}^{10}$ It has been shown that GDNF is neuroprotective after $\mathrm{SCl}^{23}$ and that NT-3 promotes growth and differentiation of neurons and synapses. ${ }^{24}$ In the current study, the expression levels of GDNF and NT-3 among Th1 cells, Th1 ifn- $\gamma^{-1-}$ cells, and Th17 cells were compared using ELISA. GDNF expression was higher in Th1 cells than that in Th1 ifn- $\gamma^{-1-}$ cells or Th17 cells (Figure $5 \mathrm{a}$ ), although expression of NT-3 was not significantly different between Th1 cells and Th1 ifn- $\gamma^{-/-}$cells (Figure 5b).

\section{Discussion}

The current study demonstrated that ifn- $\gamma$-dependent secretion of IL-10 from Th1 cells as well as from MG/MФs is required for the enhanced recovery from $\mathrm{SCl}$ induced by Th1 transfer (Figure 6). It is surprising that expression of the neuroprotective cytokine IL-10 is upregulated from MG/MФs in an ifn- $\gamma$-dependent manner (Figure 3a), although proinflammatory Th1 cells were transferred after SCl. However, effects of these cytokines especially IL-10 upregulation in the CNS are partial (Figures $3 b$ and d). Th1 cell-transferred spinal cord after $\mathrm{SCl}$ showed accumulation of activated round MG and MФs around the injured dorsal and lateral CST, although activated and ramified MG/MФs are also observed without treatment after $\mathrm{SCl}$ (Figures $2 \mathrm{a}$ and $\mathrm{b}$ ). It is suggested that the increased proportion of neuroprotective M2 MG/MФs induced by Th1 cells transfer ${ }^{10}$ may protect and repair injured neuronal fibers, including the CST. To elucidate the progression of IFN$\gamma$ from Th1 cells leading to IL-10 upregulation in MG/MФs, we treated cultured MG/MФs with Th1 CM or recombinant IFN- $\gamma$ and measured IL-10 levels (Figures $4 a-c$ ). The result suggests that Th1 cells themselves secrete abundant IL-10 and, comparatively, an unexpectedly small amount of IL-10 was secreted from MG/MФs when treated with Th1 CM. It is possible that the cell state of the cultured MG/MФs in our system may be different from in vivo MG/MФs after $\mathrm{SCl}$ (Figure 3a) and that other micro-environmental factors, such as astrocyte activity, may be required to robustly elevate IL-10 secretion from MG/MФs. Whereas experiments neutralizing $\mathrm{IL}-10$ in the CNS only attenuated the effects of Th1conditioned cells transfer (Figures $3 b$ and $d$ ), transfer of Th1-conditioned cells derived from il-10 ${ }^{-1-}$ mice showed complete abrogation of the restorative effects of Th1 cells (Figure 4d). Thus, ifn- $\gamma$-dependent secretion of IL-10 from transferred Th1 cells (Figures $4 a$ and $b$ ) may contribute to the entirety of the effects by directly shifting the CNS into a neuroprotective state ${ }^{25}$ in addition to increasing the proportion of the neuroprotective M2 subtype of MG/MФs observed and upregulation of Arg1, CD206, ${ }^{10}$ and IL-10 (Figure 6). Indeed, transfer of Th1-conditioned cells has enhanced restorative effects compared with just inducing viral expression of IL-10 in the CNS after $\mathrm{SCl}^{25}$ This may be caused by shifting systems in the periphery, such as MФs in the lymph nodes into a neuroprotective state, as well as the CNS with Th1-cell transfer. On the other hand, IFN- $\gamma$ did not have direct effects on IL-10 upregulation from MG/MФs (Figures $4 a-c$ ). We conclude that ifn- $\gamma$ is required to maintain transferred Th1 cells to abundantly secrete IL-10 rather than directly upregulating IL-10 from MG/MФs in the lesion site after SCl. Our result is consistent with a report that ifn- $\gamma$ mediates IL-10 reactivation by parasitereactive Th1 cells. ${ }^{26}$ The notion may be consistent with our previous report that IFN- $\gamma$ is necessary for maintaining Th1 cells to promote neurite outgrowth from cortical neurons rather than directly elongating neurites. ${ }^{27}$ On the other hand, other mechanism independent of ifn- $\gamma$ may be partially responsible for IL-10 secretion from Th1 cells, because comparatively very small amounts of IL-10 were still secreted from Th1 ifm ${ }^{-1-}$ cells (Figures $4 a$ and $b$ ). This residual secretion of IL-10 may be attributed to ifn- $\gamma$-independent activation of signal transducer and activator of transcription 4 , as previously reported. ${ }^{28}$ 
In general, inflammation is considered to be detrimental to the CNS injury, but there are some reports demonstrating that pro-inflammatory $\mathrm{T}$ cells are beneficial to the CNS injury. Those T cells may be attributed to the functions of Th1 cells in ifn- $\gamma$-dependent manner. Indeed, IFN- $\gamma$ promotes neuronal differentiation ${ }^{29}$ and neurogenesis. ${ }^{30}$ Secretion of IFN- $\gamma$ by the transferred Th1-conditioned cells has a role in MG activation (Figures $2 \mathrm{c}$ and d), leading to functional recovery from SCI. It has been suggested that activated MG induce neuronal differentiation $^{31}$ and are neuroprotective. ${ }^{22}$ In addition, the beneficial role of MФs in the injured CNS is known. ${ }^{32,33}$

IFN- $\gamma$ contributes to the upregulation of GDNF in Th1 cells (Figure 5a), which may have positive effects on neuroprotection after SCl. Thus, the in vivo effects of IFN- $\gamma$ secreted by Th1-conditioned cells are important for functional recovery after SCl. However, it should be noted that Th1-conditioned cells lacking IFN- $\gamma$ still had limited beneficial effects (Figures $1 \mathrm{c}$ and $\mathrm{d}$ ). These remnant effects may be mediated by neuroprotective IL-10 (Figures $4 a$ and $b$ ) and trophic factors, such as NT-3 (Figure 5b).

Taken together, pro-inflammatory Th1 cells have restorative effects on functional recovery after $\mathrm{SCl}$ in ifn- $\gamma$ - and il-10dependent manner. There are many side effects after massive dose of glucocorticoid treatment such as increased susceptibility to infection, gastroinstestinal ulcer, diabetes mellitus, and mental disorder. Therefore, our study provides new insights into future immunomodulatory treatment after CNS trauma (for example, transfer of Th1 cells or skewing to Th1), which not only promotes beneficial immune reactions but also attenuates harmful ones such as devastating Th17 cells.

\section{Materials and Methods}

Mice. C57BL/6j mice were purchased from Charles River Laboratories (Wilmington, MA, USA). As previously reported, ifn- $\gamma^{-1-}$ mice ${ }^{34}$ and $i l-10^{-1-}$ mice ${ }^{35}$ on the C57BL/6 background were used. All mice used in this study were housed in specific pathogen-free conditions and were treated and cared for in accordance with the guidelines of Osaka University pertaining to the treatment of experimental animals.

Animal model of SCI. Adult (7-9 weeks old) female C57BL/6 mice were anesthetized with sodium pentobarbital $(50 \mathrm{mg} / \mathrm{kg}$; Kyoritsu Seiyaku, Tokyo, Japan). Following dorsal laminectomy (at the T9-T10 level), the spinal cord was contused with a force of $60 \mathrm{kdyn}$ using an Infinite Horizon Impactor (Precision Systems \& Instrumentation, Fairfax Station, VA, USA), as previously described. ${ }^{36}$ The muscle and skin layers were then sutured. The bladder was expressed daily using manual abdominal pressure until 10 days after injury. Food and water were provided ad libitum.

Adoptive transfer of cultured T cells. The procedure was performed according to a previously described procedure. ${ }^{10}$ The procedure is briefly indicated as following: spleens were collected from the mice. $\mathrm{CD} 4^{+} \mathrm{T}$ cells were isolated using magnet sorting with anti-CD4 magnet beads (Miltenyi Biotec, Cologne,

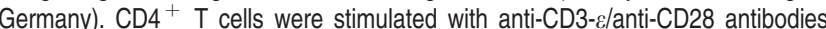
$(5 \mu \mathrm{g} / \mathrm{ml}$, respectively, eBioscience, San Diego, CA, USA) coated on 24-well plates (Greiner Bio-One, Kremsmünster, Austria). Th1-conditioned cells were differentiated by the addition of recombinant IL-2 $(25 \mathrm{U} / \mathrm{ml}$; R\&D Systems/TECHNE, Minneapolis, MN, USA), IL-12 (10 U/ml; R\&D systems), and anti-IL-4 antibodies (25\% culture supernatant of hybridoma; clone HB-188; American Type Culture Collection, Manassas, VA, USA). Th17-conditioned cells were differentiated by the addition of recombinant IL-6 (20 ng/ml; R\&D systems), IL-23 $(20 \mathrm{ng} / \mathrm{ml}$; R\&D systems), TGF- $\beta 1$ ( $3 \mathrm{ng} / \mathrm{ml}$; R\&D systems), anti-IL-4 antibodies ( $25 \%$ culture supernatant of the hybridoma), and anti-IFN- $\gamma$ antibodies ( $1 \%$ culture supernatant of hybridoma; clone HB-170; American Type Culture Collection) in the presence of
anti-IL-2 antibody $(10 \mu \mathrm{g} / \mathrm{ml}$; R\&D Systems). Th0 cells were cultured in the presence of only IL-2 $(25 \mathrm{U} / \mathrm{ml}$; R\&D Systems). On day 4 , the helper T cells were collected. The cells were centrifuged at $1000 \times g$ for 20 min with Lympholyte-M (Cedarlane Laboratories, Burlington, Ontario, Canada), and the intermediate layer was collected to eliminate the dead cells. The cells were restimulated for $3 \mathrm{~h}$ with anti-CD3- $\varepsilon$ and anti-CD28 antibodies. On day 4 after SCI, helper T cells $\left(1.0 \times 10^{7}\right)$ suspended in $500 \mu \mathrm{l}$ phosphate-buffered saline (PBS) were injected i.p. into mice. As a control, $500 \mu \mathrm{l}$ PBS was injected into mice after SCI.

Behavioral analysis. Hindlimb motor function was evaluated using the BMS open-field locomotor test, in which scores range from 0 to $9 .{ }^{18}$ BMS scores were recorded on days 1,3 , and 7 after injury, and once weekly thereafter for a total of 6 weeks.

The grid-walk test was also performed to evaluate hindlimb locomotion. ${ }^{19}$ Deficits in descending motor control were examined by assessing the ability of mice to step on a square framework, $26 \mathrm{~cm}$ on a side, consisting of $1-\mathrm{cm}^{2}$ grids made of round metal bars. Analysis was performed by counting the number of errors (that is, dropping the hindlimb from the grid) in 50 steps for each hindlimb. The mean percentage of errors was then calculated. Error percentages were not calculated before 2 weeks after $\mathrm{SCl}$ because, before this time, animals were unable to move their hindlimbs owing to insufficient recovery.

A subset of animals was analyzed using the inclined-plane test, ${ }^{10}$ which evaluates the animal's ability to maintain body position on a board raised incrementally to increasing angles. Performance on the inclined plane correlates with the integrity of the rubrospinal tract (and other nonpyramidal pathways) after $\mathrm{SCl}$. Animals were tested at days 1, 3, 7 after injury, and once weekly thereafter for a total of 6 weeks. Mice were tested in each position, after which the angle was increased incrementally by $5^{\circ}$. The maximum angle at which the animal could maintain a stationary position on the board for $10 \mathrm{~s}$ was recorded. Investigators were blinded to the treatment protocol and recorded behavioral scores.

Tissue preparation and histochemistry. For histochemistry, animals were perfused with $4 \%$ paraformaldehyde and preserved spinal cord tissues were collected. The entire spine was dissected out and post-fixed in $4 \%$ paraformaldehyde for $3 \mathrm{~h}$ at $4{ }^{\circ} \mathrm{C}$. The spinal cord was removed from the vertebral column and stored for $12 \mathrm{~h}$ in $15 \%$ sucrose in $0.2 \mathrm{M}$ PBS at $4{ }^{\circ} \mathrm{C}$. The spinal cord was then placed in $30 \%$ sucrose in $0.2 \mathrm{M}$ PBS for $24 \mathrm{~h}$ at $4{ }^{\circ} \mathrm{C}$. The spinal cord was embedded in Tissue Tek OCT compound (Sakura, Tokyo, Japan) and immediately frozen on dry ice at $-80^{\circ} \mathrm{C}$. A series of $20-\mu \mathrm{m}$ transverse sections were cut on a cryostat and mounted on Matsunami Adhesive Silan-coated glass slides (Matsunami Glass, Osaka, Japan). After washing three times with PBS, all sections were blocked in PBS containing 5\% BSA and $0.3 \%$ Triton $\mathrm{X}-100$ for $1 \mathrm{~h}$ at room temperature. The sections were then incubated with polyclonal anti-lba1 antibody $(1: 200$; Wako, Osaka, Japan) overnight at $4{ }^{\circ} \mathrm{C}$, washed three times with PBS, and incubated with fluorescein-conjugated secondary antibodies (1:500; Life Technologies, Carlsbad, CA, USA) for $1 \mathrm{~h}$ at room temperature. Sections were then rinsed three times in PBS and mounted. The sections were viewed under an inverted light microscope equipped with epifluorescence optics and a dry condenser for phase-contrast microscopy (DP70, Olympus, Tokyo, Japan).

Preparation of leukocytes from injured spinal cords. The extraction of leukocytes from the spinal cord was performed according to a previously described procedure. ${ }^{37}$ First, mice were transcardially perfused with icecold PBS. The spinal cord was then dissected and suspended in Hank's Balanced Salt Solution (Life Technologies) supplemented with $3 \%$ fetal bovine serum (FBS), $100 \mathrm{IU} / \mathrm{ml}$ penicillin, and $100 \mu \mathrm{g} / \mathrm{ml}$ streptomycin. The spinal cords were digested with collagenase $D(5.0 \mathrm{mg} / \mathrm{ml}$; Roche Diagnostics, Tokyo, Japan) plus $2.5 \mathrm{mM}$ calcium chloride. After filtration with a $70-\mu \mathrm{m}$ Cell Strainer (BD Biosciences, Franklin Lakes, NJ, USA), lysis of red blood cells with RBC Lysis Buffer (BioLegend, San Diego, CA, USA) and washing, the pellet, isolated by $38 \%$ Percoll centrifugation at $1500 \times g$ for 20 min, was collected for flow cytometry.

Cell-surface and intracellular antigen staining. Cultured lymphocytes or collected leukocytes from mouse spinal cords were stimulated with $50 \mathrm{ng} / \mathrm{ml}$ phorbol 12-myristate 13-acetate (Sigma-Aldrich, St. Louis, MO, USA) and $750 \mathrm{ng} / \mathrm{ml}$ ionomycin (Calbiochem/EMD Millipore, Billerica, MA, USA) for $4 \mathrm{~h}$ and with $10 \mu \mathrm{g} / \mathrm{ml}$ brefeldin A (Sigma-Aldrich) for the last $2 \mathrm{~h}$. The cells were suspended in Fixation Buffer (eBioscience) and surface stained with anti-CD45Alexa647 (BioLegend) and anti-CD11b-PE (BioLegend). Intracellular staining was 
performed according to the manufacturer's protocol, using anti-T-bet-PE (eBioscience) and anti-IL-10-FITC (BioLegend).

Flow cytometric analysis. Flow cytometry was performed with the FACSCalibur flow cytometer (BD Biosciences), and was analyzed using ProQuest (BD Biosciences) and FlowJo software (TreeStar, Ashland, OR, USA). Control experiments using isotype-matched immunoglobulins (BioLegend) were performed to determine the specificity of the signals of antibodies against specific antigens.

Infusion i.c.v. Following $\mathrm{SCl}$, the right lateral ventricle of the mouse was stereotaxically perforated with a brain infusion kit 3 (ALZET, DURET Corporation, Cupertino, CA, USA; coordinates: $0.5 \mathrm{~mm}$ posterior to the bregma, $1.0 \mathrm{~mm}$ lateral to the bregma, $2 \mathrm{~mm}$ deep) and connected to an osmotic minipump (ALZET; pump model: 1007D) filled with $1 \mathrm{mg} / \mathrm{ml}$ anti-IL-10-neutralizing antibody (eBioscience; clone: JES5-16E3) or rat IgG (eBioscience). The anti-IL-10 antibody was infused for 7 days.

Culture of MG/MФs and treatment of T-cell culture media. Culture of $M G$ and MФs was performed according to a previously described procedure. ${ }^{38}$ $M G$ were obtained from the brain of C57BL/6j mice on postnatal day $1-2$. The cerebral cortex of each mouse was dissected out and the meninges were eliminated. The brains were minced with surgical knives, and then digested with $0.25 \%$ trypsin for $15 \mathrm{~min}$ and $0.5 \mathrm{mg} / \mathrm{ml}$ DNase for the last $1 \mathrm{~min}$ at $37^{\circ} \mathrm{C}$. The cells were passed through a 70- $\mu \mathrm{m}$ Cell Strainer (BD Biosciences). The resultant cell suspension was diluted with Dulbecco's Modified Eagle Medium (DMEM; Life Technologies) and spun down. The pellet was suspended with 10\% FBS/1\% penicillin and streptomycin/DMEM (DMEM growth medium) and plated on poly-Llysine-coated $75-\mathrm{cm}^{3}$ culture flask (Greiner Bio-One). On day 1 and every 3 days thereafter, DMEM growth medium was replaced. After $>7$ days, the flask was shaken for $30 \mathrm{~min}$ so that floating MG could be collected from the astrocyte monolayer sheet and cultured at the density of $3.3 \times 10^{4}$ cells in $100 \mu$ l growth medium for 1 well of 96 -well plate (Greiner Bio-One). More than $90 \%$ of the cells were $\mathrm{CD} 11 \mathrm{~b}^{+} \mathrm{MG}$.

Bone marrow-derived MФs were obtained from bilateral femoral bones of 9 week-old C57BL6/j mice. Marrow cores were flushed using 10-ml syringes filled with RPMl1640 (Invitrogen)/10\% FBS. After trituration and lysis of red blood cells with RBC Lysis Buffer (BioLegend), the cells were washed in the medium, and then plated and cultured in RPMl1640 with 10\% FBS, penicillin/streptomycin (RPMI growth medium), and M-CSF (50 ng/ml; BioLegend). Non-adherent cells were collected at day 4 . On day 6 , the cells were replated on 96 -well plates at the density of $3.3 \times 10^{4}$ cells in $100 \mu$ l of RPMI growth medium for one well. On day 7 , the cells were treated with the T-cell supernatant. More than $90 \%$ of the cells were CD11b ${ }^{+}$MФs.

One hundred microliters of $\mathrm{CM}$ of cultured T cells (collected 4 days after

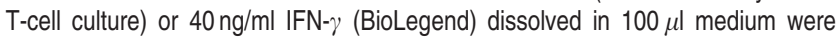
applied to MG or MФs cultured as above. At 0, 1, 3, 6, and $24 \mathrm{~h}$ after treatment of T-cell CM, supernatant of the cultured cells were collected to detect IL-10 with ELISA.

Enzyme-linked immunosorbent assay. Th1, Th1 ifn- ${ }^{-/-}$, and Th17 cells were prepared as described above. Three hours after restimulation with antiCD3- $\varepsilon / a n t i-C D 28$ antibodies, cells were centrifuged and their supernatants were collected and stored at $-80^{\circ} \mathrm{C}$ until use. Concentrations of IFN- $\gamma$, IL-10, NT-3, and GDNF in the supernatants of each cell were analyzed using the ELISA kits, according to the manufacturer's protocol (IFN- $\gamma$ and IL-10: R\&D Systems; NT-3: Emax Immunoassay System; GDNF: Promega, Fitchburg, WI, USA). Absorbance values were read at $450 \mathrm{~nm}$ on a plate reader (SpectraMax M2; Molecular Devices, Sunnyvale, CA, USA).

Statistical analysis. All values are expressed as mean \pm S.E.M. Motor function scores were analyzed using two-way ANOVA with repeated measures with a Bonferroni post-test for 2-3 groups. For all other data, a one-way ANOVA with a Bonferroni post-test collection was used. Values of $P<0.05$ were considered statistically significant.

\section{Conflict of Interest}

The authors declare no conflict of interest.
Acknowledgements. We thank Drs. T Nakayama, M Yamashita, and M Kuwahara at Chiba University for their technical advice on T-cell culture; Drs. K Morimoto and S Lee at Osaka University for their help in histological assessment; Ms Nakamura at Osaka University for her advise on surgical procedure; Dr. Y Souma at the National Institute of Biomedical Innovation for taking care of the IFN- $\gamma$ knockout mice; and Drs. $\mathrm{H}$ lijima, A Mukai, $\mathrm{H}$ at Osaka University for advice on knockout mice. This work was supported by a research grant from a Grant-in-Aid for Young Scientists (S) from the Japan Society for the Promotion of Science (JSPS).

1. David S, Aguayo AJ. Axonal elongation into peripheral nervous system 'bridges' after central nervous system injury in adult rats. Science 1981; 214: 931-933.

2. Bye N, Habgood MD, Callaway JK, Malakooti N, Potter A, Kossmann T et al. Transient neuroprotection by minocycline following traumatic brain injury is associated with attenuated microglial activation but no changes in cell apoptosis or neutrophil infiltration. Exp Neurol 2007; 204: 220-233.

3. Beck KD, Nguyen HX, Galvan MD, Salazar DL, Woodruff TM, Anderson AJ. Quantitative analysis of cellular inflammation after traumatic spinal cord injury: evidence for a multiphasic inflammatory response in the acute to chronic environment. Brain 2010; 133: 433-447.

4. Donnelly DJ, Popovich PG. Inflammation and its role in neuroprotection, axonal regeneration and functional recovery after spinal cord injury. Exp Neurol 2008; 209: 378-388.

5. Potas JR, Zheng Y, Moussa C, Venn M, Gorrie CA, Deng C et al. Augmented locomotor recovery after spinal cord injury in the athymic nude rat. J Neurotrauma 2006; 23: 660-673.

6. Shichita T, Sugiyama Y, Ooboshi H, Sugimori H, Nakagawa R, Takada I et al. Pivotal role of cerebral interleukin-17-producing gammadeltaT cells in the delayed phase of ischemic brain injury. Nat Med 2009; 15: 946-950.

7. Hofstetter HH, Sewell DL, Liu F, Sandor M, Forsthuber T, Lehmann PV et al. Autoreactive $T$ cells promote post-traumatic healing in the central nervous system. $J$ Neuroimmunol 2003; 134: 25-34.

8. Ziv Y, Ron N, Butovsky O, Landa G, Sudai E, Greenberg N et al. Immune cells contribute to the maintenance of neurogenesis and spatial learning abilities in adulthood. Nat Neurosci 2006; 9: 268-275.

9. Chiu IM, Chen A, Zheng Y, Kosaras B, Tsiftsoglou SA, Vartanian TK et al. T lymphocytes potentiate endogenous neuroprotective inflammation in a mouse model of ALS. Proc Natl Acad Sci USA 2008; 105: 17913-17918.

10. Ishii H, Jin X, Ueno M, Tanabe S, Kubo T, Serada S et al. Adoptive transfer of Th1conditioned lymphocytes promotes axonal remodeling and functional recovery after spinal cord injury. Cell Death Dis 2012; 3: e363.

11. Hendrix $\mathrm{S}$, Nitsch $\mathrm{R}$. The role of $\mathrm{T}$ helper cells in neuroprotection and regeneration. J Neuroimmunol 2007; 184: 100-112.

12. Derecki NC, Cardani AN, Yang CH, Quinnies KM, Crihfield A, Lynch KR et al. Regulation of learning and memory by meningeal immunity: a key role for IL-4. J Exp Med 2010; 207: 1067-1080.

13. Kebir $\mathrm{H}$, Kreymborg $\mathrm{K}$, Ifergan I, Dodelet-Devillers $\mathrm{A}$, Cayrol R, Bernard M et al. Human TH17 lymphocytes promote blood-brain barrier disruption and central nervous system inflammation. Nat Med 2007; 13: 1173-1175.

14. Hafler DA. Multiple sclerosis. J Clin Invest 2004; 113: 788-794.

15. Fransson ME, Liljenfeldt LS, Fagius J, Tötterman TH, Loskog AS. The T-cell pool is anergized in patients with multiple sclerosis in remission. Immunology 2009; 126: 92-101.

16. $\mathrm{Hu} \mathrm{X}$, Ivashkiv LB. Cross-regulation of signaling pathways by interferon-gamma: implications for immune responses and autoimmune diseases. Immunity 2009; 31 539-550.

17. Mullen AC, High FA, Hutchins AS, Lee HW, Villarino AV, Livingston DM et al. Role of T-bet in commitment of TH1 cells before IL-12-dependent selection. Science 2001; 292 1907-1910.

18. Basso DM, Fisher LC, Anderson AJ, Jakeman LB, McTigue DM, Popovich PG. Basso Mouse Scale for locomotion detects differences in recovery after spinal cord injury in five common mouse strains. J Neurotrauma 2006; 23: 635-659.

19. Metz GA, Merkler D, Dietz V, Schwab ME, Fouad K. Efficient testing of motor function in spinal cord injured rats. Brain Res 2000; 883: 165-177.

20. Ford AL, Goodsall AL, Hickey WF, Sedgwick JD. Normal adult ramified microglia separated from other central nervous system macrophages by flow cytometric sorting. Phenotypic differences defined and direct ex vivo antigen presentation to myelin basic protein-reactive CD4 + T cells compared. J Immunol 1995; 154: 4309-4321.

21. Liesz A, Suri-Payer E, Veltkamp C, Doerr H, Sommer C, Rivest S et al. Regulatory T cells are key cerebroprotective immunomodulators in acute experimental stroke. Nat Med 2009; 15: 192-199.

22. David S, Kroner A. Repertoire of microglial and macrophage responses after spinal cord injury. Nat Rev Neurosci 2011; 12: 388-399.

23. Iannotti C, Ping Zhang Y, Shields $C B$, Han Y, Burke DA, Xu XM. A neuroprotective role of glial cell line-derived neurotrophic factor following moderate spinal cord contusion injury. Exp Neurol 2004; 189: 317-332.

24. Ghosh A, Greenberg ME. Distinct roles for bFGF and NT-3 in the regulation of cortical neurogenesis. Neuron 1995; 15: 89-103. 
25. Zhou Z, Peng X, Insolera R, Fink DJ, Mata M. IL-10 promotes neuronal survival following spinal cord injury. Exp Neurol 2009; 220: 183-190.

26. Saraiva M, Christensen JR, Veldhoen M, Murphy TL, Murphy KM, O'Garra A. Interleukin10 production by Th1 cells requires interleukin-12-induced STAT4 transcription factor and ERK MAP kinase activation by high antigen dose. Immunity 2009; 31: 209-219.

27. Ishii H, Kubo T, Kumanogoh A, Yamashita T. Th1 cells promote neurite outgrowth from cortical neurons via a mechanism dependent on semaphorins. Biochem Biophys Res Commun 2010; 402: 168-172.

28. Shaw MH, Freeman GJ, Scott MF, Fox BA, Bzik DJ, Belkaid $Y$ et al. Tyk2 negatively regulates adaptive $\mathrm{Th} 1$ immunity by mediating $\mathrm{IL}-10$ signaling and promoting IFN-gamma-dependent IL-10 reactivation. J Immunol 2006; 176: 7263-7271.

29. Wong G, Goldshmit Y, Turnley AM. Interferon-gamma but not TNF alpha promotes neuronal differentiation and neurite outgrowth of murine adult neural stem cells. Exp Neurol 2004; 187: 171-177

30. Baron R, Nemirovsky A, Harpaz I, Cohen H, Owens T, Monsonego A. IFN-gamma enhances neurogenesis in wild-type mice and in a mouse model of Alzheimer's disease. FASEB J 2008; 22: 2843-2852.

31. Butovsky O, Ziv Y, Schwartz A, Landa G, Talpalar AE, Pluchino S et al. Microglia activated by IL-4 or IFN-gamma differentially induce neurogenesis and oligodendrogenesis from adult stem/progenitor cells. Mol Cell Neurosci 2006; 31: 149-160.

32. Shechter R, London A, Varol C, Raposo C, Cusimano M, Yovel G et al. Infiltrating blood-derived macrophages are vital cells playing an anti-inflammatory role in recovery from spinal cord injury in mice. PLOS Med 2009; 6: e1000113.

33. Kigerl KA, Gensel JC, Ankeny DP, Alexander JK, Donnelly DJ, Popovich PG. Identification of two distinct macrophage subsets with divergent effects causing either neurotoxicity or regeneration in the injured mouse spinal cord. J Neurosci 2009; 29: 13435-13444.

34. Horino J, Fujimoto M, Terabe F, Serada S, Takahashi T, Soma Y et al. Suppressor of cytokine signaling-1 ameliorates dextran sulfate sodium-induced colitis in mice. Int Immunol 2008; 20: 753-762

35. Hirotani $T$, Lee PY, Kuwata $H$, Yamamoto $M$, Matsumoto $M$, Kawase I et al. The nuclear IkappaB protein IkappaBNS selectively inhibits lipopolysaccharideinduced IL-6 production in macrophages of the colonic lamina propria. J Immunol 2005; 174: 3650-3657.

36. Engesser-Cesar C, Anderson AJ, Basso DM, Edgerton VR, Cotman CW. Voluntary wheel running improves recovery from a moderate spinal cord injury. J Neurotrauma 2005; 22: 157-171.

37. Serada S, Fujimoto M, Mihara M, Koike N, Ohsugi Y, Nomura S et al. IL-6 blockade inhibits the induction of myelin antigen-specific Th17 cells and Th1 cells in experimental autoimmune encephalomyelitis. Proc Natl Acad Sci USA 2008; 105: 9041-9046.

38. Kitayama M, Ueno M, Itakura T, Yamashita T. Activated microglia inhibit axonal growth through RGMa. PLoS One 2011; 6: e25234.

(c) (2) Cell Death and Disease is an open-access journal published by Nature Publishing Group. This work is licensed under a Creative Commons Attribution-NonCommercialShareAlike 3.0 Unported License. To view a copy of this license, visit http://creativecommons.org/licenses/by-nc-sa/3.0/ 